International Journal of Linguistics, Literature and Culture
Available online at https://sloap.org/journals/index.php/ijllc/
Vol. 6, No. 6, November 2020, pages: 48-57
$\begin{aligned} & \text { ISSN: } 2455-8028 \\ & \text { https://doi.org/10.21744/ijllc.v6n6.1036 }\end{aligned}$

\title{
Derived Verbs with Suffix -ang in Balinese: Syntactic and Semantic Analysis
}

Article history:

Submitted: 09 September 2020

Revised: 27 October 2020

Accepted: 18 November 2020

\section{Keywords:}

morphology;

regional languages;

semantic analysis;

suffix-ang;

syntactic;

\begin{abstract}
This paper accounts for the suffix -ang in Balinese and it focuses on its syntactic and semantic representation. Using I Madé's Sugianto's Ki Bari Gajah, a one hundred fifty-page Balinese novel and informants as the data, and applying the RRG theory by Van Valin and Randy (1997) other thoughts of the experts of Balinese, it was found out that -ang functioning as a transitivizing suffix can attach to the noun, adjective, adverbs, and verbs and imply various syntactic structures and semantic representations. Suffix -ang attached to the base in imperative sentences express no meaning. In this case, it is just used to imply that the sentence is in the form of imperative. Like other languages, English for example, one derived verb with -ang may be used transitively or intransitively.
\end{abstract}

International journal of linguistics, literature and culture (C) 2020. This is an open access article under the CC BY-NC-ND license (https://creativecommons.org/licenses/by-nc-nd/4.0/).

\section{Corresponding author:}

Nyoman Sujaya,

Warmadewa University, Denpasar, Indonesia.

Email address:nyomansujaya753@gmail.com

\footnotetext{
a Warmadewa University, Denpasar, Indonesia

${ }^{\mathrm{b}}$ Warmadewa University, Denpasar, Indonesia
} 


\section{Introduction}

Balinese is one of the larger regional languages in the middle part of Indonesia. This language is mainly spoken by Balinese people living in Bali. It is spoken by around 3,247,283 speakers, about $77 \%$ of the population of Bali, which was recorded as 4.2 million.

Balinese is categorized as a synthetic language in which morphology plays an important role. Its word-formation involves derivation, inflection, duplication, reduplication, and compound. Affixation by the suffix -ang or -in, for example, can deal with more than one type of word formation, they can function either as derivations or infections (Kersten, 1984).

It is known that the morphology of Balinese verbs is very simple; there is no tense, no infinitive, and no active participle in Balinese. However, in Balinese, there is a means of distinguishing between active and passive voice; by affixation, which in practice they can be used without any difficulty.

Although the morphology of Balinese verbs is simple, in practice its usage is very complicated because it involves pre and post modification, that is by the attachment of affixes or left unsuffixed (Arka, 1998; Suryati, 1997). This condition brings various semantic representations: e.g. banten offering' ma-banten 'do offering' $m$-(b)antenang 'do offering for someone else' $m$-(b)anten-in 'do offering to an object', banten-ang 'offer!', banten-in 'do offering at', banten-in- $a$ 'do offering at', ka-banten-ang 'be offered', banten-ang-a ajak...'be offered by ...'. Sometimes, in certain expressions, the subjects or objects are not expressed, but the context and the social culture make them understood or clear in meaning.

To sentence construction, Balinese involve morphological unmarked basic verbs and nasal verb forms. According to Artawa (2013), the word order of the basic verb form is Patient-Verb-Agent oriented, while the nasal construction is Agent-Verb-Patient. According to Wechsler \& Arka (1998), it is stated that Balinese has nasal and basic verb forms. Its complex variation of verb forms shows morphological distinct kinds of prefixes and suffixes which bring various constructions with various semantic representations.

In recent years, some researchers have discussed Balinese syntax. For example, Arka (2005), discussed speech levels, social predicates, and pragmatic structure in Balinese, Indrawati (2011), discussed Balinese serial verbs construction, Artawa (2013) examined the basic verb constructions of Balinese, Kardana \& Satyawati (2014), analyzed about Morphosyntax of Balinese Reciprocal Constructions, Bagus (2018) analyzed Intransitive verb makers in Balinese, Pratiwi et al. (2018), wrote about On The Situated Socio-Cultural Meaning Of Benefactives In Balinese, and Sujaya \& Satyarini (2020), discussed The Constructions of Balinese "Giving” Verbs.

The researchers mentioned above talked about the grammar of Balinese (Foley, 2009; Quirk, 2010). They talked about syntactic analysis which, theoretically, cannot be separated from semantic and pragmatic perspectives. They also talked about how the morphosyntax works. However, they have not discussed the Balinese suffix, namely -ang. They haven't talked about syntactic and semantic analysis of suffix -ang in more detail. It is based on this reason so that serious study on it is necessary to be conducted.

The focus of this study is on the syntactic and semantic analysis of suffix -ang. It is about its modifications and the meaning assigned. It deals with its constructions and its semantic representation. The structure of this paper is as follows: section 1 is about the introduction, in section 2 there will be a brief discussion of Balinese verb morphology, section 3 is about the research method, section 4 is about a detailed discussion of the constructions with the suffix -ang, then, finally, in section 5, there will be the concluding remarks (Intiana, 2017).

\section{The Morphology of Balinese Verbs}

What is discussed in this section is about the understanding of Balinese morphology in general (Hunter Jr, 1988; Sedeng, I.N. 2007). It involves the specific form of precategorial, basic verbs, and the derived ones. The morphology of the Balinese verb is extremely simple; it has no conjugations, no system forms to mark the person or number of the subject or the tense or mood of the verb itself; it has no infinitives, no active participles. However, it has the means of distinguishing between active and passive voice.

The morphology of the verb must begin with the base; this is usually the root-word whose function is to indicate an action or being in a condition (Friederici, 2004; Melinger \& Dobel, 2005). Many such bases are also used as nouns, adjectives, or adverbs. Similarly, roots that are primarily nouns, adjectives, or adverbs, may act as bases for verbs. Verb-bases may also be nouns made up of prefix + root (+ suffix): tutur 'tell', pitutur 'narrative', pituturin 'be narrated to someone', mituturin 'narrate to someone'. Even phrases may act as bases for verbs: telu bulan 'three

Sujaya, N. ., \& Sukiani, N. K. . (2020). Derived verbs with suffix -ang in Balinese: syntactic and semantic analysis. International Journal of Linguistics, Literature and Culture, 6(6), 48-57.

https://doi.org/10.21744/ijllc.v6n6.1036 
months': matelubulanan 'be 3 months old'; das lemah 'early in the day', ngedaslemahang 'do (something) early in the day'.

Balinese, like many other languages in Indonesia, has basic and derived verbs (Warna, 1983). Besides these two kinds of verb construction, there is also the existence of what Artawa calls 'precategorial' roots (Artawa 1994), a lexical form which will only have a verbal lexical function if it is attached with prefix $N$ - or suffix -ang or -in. Take the form tegak 'sit' as an example. This form will function syntactically if it is derived like in the following examples.

(1) a. *Ia tegak di bucu

3SG sit in corner

'He sat in the corner'

b. Ia negak di bucu

3SG sit in corner

'He sat in the corner'

c. Ia n-(t)egak-in kursi

3SG AF-sit-APPL chair

'He sat on the corner'

Tegak in data (1) a belongs to precategorial. This form has no meaning in Balinese but it will have meaning if it is attached by affixation like in the data (1) b and c.

Basic verb

Basic verb, in Balinese called keruna lingga, is a base form with no affixation and reduplication. The basic verb can be classified into transitive or ditransitive.

(2) a. Kuluk-é idih tiang

Dog-DEF ask for $1 \mathrm{SG}$

'I asked for your dog'
b. Poh-é amah lelawah
Mangoes-DEF eat bats
'Bats ate the manggoes'

The base, the basic form of the verb, is the fundamental root-form of the word that carries meanings and constitutes the Balinese verb-system. This base, unmodified, is by no means always and unmistakably a verb. In a context, this base may be performing any one of some different grammatical functions, not distinguished from each other by morphological signs (Barber, 1974).

The basic form can also be intransitive active, imperative active, or passive; The N-form is usually transitive active. The essential feature of the $\mathrm{N}$-form is that it shows that the speaker is concerned with what the subject of the transitive is doing; he may be doing something to an object, but the speaker is not concerned with this. It is because of this that the N-form is used in many sentences which have no direct object; geling 'weep': ngeling 'he is weeping'; if an object is mentioned the verb must be ngelingin 'he is weeping-for her' (Barber, 1974).

\section{Derived verb}

A derived verb is a verb formed through the attachment of affixes. It may involve the addition of prefix $N$-, $m a$-, $k a-$, $p a$ - pati- suffix $-a$, - ang,-in and the combination of $m a--a n$. The nasal $(N-)$ occurring with roots (which may be an adjective, a noun or a verb has the allomorphs $n g-, n y, n-, m-$, and $n g a$ - depending on the first phoneme of the root (Warna, 1983).

Examples:
alih
'find' ngalih 'to find'
sampat
'broom' nyampat 'to sweep' 


$\begin{array}{llll}\text { tusuk 'penetrate' } & \text { nusuk } & \text { 'to penetrate' } \\ \text { pancing 'fising rod' } & \text { mincing 'to fish' } & \\ \text { maling } & \text { 'theaf' } & \text { ngamaling } & \text { 'to steal' }\end{array}$

In Balinese, derived verbs can be transitive or intransitive. A transitive can be mono transitive or ditransitive (verb with three arguments). Freebase verbs and bound verbs can become the verb of three arguments through morphological processes, namely suffixation of an applicative. Let us have a look at the following examples.

(3) a. Panak tiang-é sampun ma-gaé

Son 1SG-POSS already AF-work

'My son has already got a job'

b. Mén Sukasih N-gaé baju

Mother Sukasih AF-work dress

'Mother Sukasih made shirts'

c. Ia N-gaé-ang panak-né baju

3SG AF-wor-Trans. doughter-POSS dress

'She made her doughter a dress'

One other morphological feature is the suffix $-a$, which is very frequent in speech, but rare in literary works, since it belongs, and is felt by the Balinese to belong, to basa ketah. When added to a noun, $-a$ is a possessive pronominal suffix. The form umaha means his/her house. When added to an active transitive verb, it expresses a pronominal object in the third person. Biuné lablaba means 'He boiled his bananas'. When added to a passive verb, it indicates that the agent is kept in mind, even if not expressed, and that the agent is not the speaker or the person addressed. The form enot means 'seen, visible' or 'was seen', but enota means 'was seen by someone (whose identity is known from the context)' (Barber, 1974).

\section{Materials and Methods}

As mentioned previously, the focus of this paper is the syntactic structure and semantic representation of suffix -ang in Balinese. The method applied in this study is a descriptive qualitative method with a 150 page-long novel called Ki baru Gajah written by I Madé Sugianto (2015) used as the data of this study. This novel consists of 27 palets 'sections' or chapters. The reason for choosing this novel as the data of this research is that this novel uses all kinds of Balinese register (low, middle, and high). Besides this novel, this research also uses informants (native speakers) to support the data.

The analysis was done by applying the RRG theory proposed by Van Valin \& Randy (1997). In this case, the notion of morphosyntactic structure is used. It is stated that if we are to capture linguistic regularities it is necessary to look at the morphosyntax, not just the syntax or morphology. The analysis was to show how the suffix -ang works in the Balinese sentence constructions. Its syntactic analysis was also to show how the grammatical structures imply the semantic representations (Yalcinkaya \& Singh, 2015; Yeh et al., 2005; Zupanc \& Bosnić, 2017). It is hoped the analysis can also be seen from its communicative functions. For this purpose, besides the theory mentioned above, other theories like the theory of semantic approach from Dixon (2005), and the theory of information structure from Lambrecht (1996), are also applied in this study.

\section{Results and Discussions}

In Balinese, -ang functioning as a transitivizing suffix may also function as an imperative marker. This suffix, when attaches to verbs, implies the object is mobile. It is quite different from suffix -in, in which the object is immobile. As a transitivizing suffix, -ang can attach to different categories: noun in buku-ang 'write on a book'; an adjective in tegeh-ang 'make high'; adverb in kelod-ang 'move north'; and verb in jagur-ang 'punch someone for someone else'.

Sujaya, N. ., \& Sukiani, N. K. . (2020). Derived verbs with suffix -ang in Balinese: syntactic and semantic analysis. International Journal of Linguistics, Literature and Culture, 6(6), 48-57.

https://doi.org/10.21744/ijllc.v6n6.1036 
And these morphological kinds of verb forms bring or imply different distinct constructions and meanings. After the data were observed and analyzed, the result shows the following constructions.

\subsection{Stative verbs with suffix -ang}

When attaches to an adjective or adverb, suffix - ang mostly expresses the meaning of 'become' or 'make more...'. The derived verbs are always in nasal forms. Syntactically, suffix -ang attaches to those class of words forms the constructions like in the following data.

(4) a. Panak-é suba N-(t)egeh-ang.

Child-DEF already AF-tall-Trans.

'Our child has become taller'

b. Ia Ng-(k)aja-nang.

3S AF-South-Trans.

'He/She is going South'

The data above shows that in (4) a, the verb negehang 'becomes tall' is formed from the adjective base tegeh 'tall' attached with -ang and combined with the nasal prefix. -ang in this case is used to form a stative intransitive sentence. - ang in this context implies causative meaning. The stative verb ngajanang 'go South' in (4) b is formed from the adverb base kaja 'South' attached with -ang and added by nasal prefix also expresses causative meaning.

\subsection{Suffix -ang in transitive construction}

As mentioned previously, the suffix - ang can function as a transitivizer. To this, -ang can attach to the noun, adjective, adverb, intransitive, and transitive bases. In this case, the derived verbs are in the nasal forms. These forms imply various constructions and meanings like in the following discussions. The verbs indeed added with -ang concentrate the action on the object, the suffix has to be interpreted as implying an object.

\subsection{1 - ang attach to noun}

Whatever word-class - ang attaches, if the derived verbs are active indicative and transitive and they are in the $\mathrm{N}$-form. Some data of -ang attached to nouns can be seen in the following data.

(5) a. Mula patut semeton kelihan $m$-(p)ica-(y)-ang tongos tekén adi-né (2)

Yes right brothers older AF.-gift-Trans. place with brother-POSS

'It is true that older brother gives place to his younger brother'

b. Ditu nyén dadi nabdab jagat $\quad N$-(t)itah-ang panjak (2)

There who can govern universe AF-.lead-Trans. Society

'There, anyone can govern kingdom leading its society'

c. Yén ba Ng-orta-ang ané jaruh-jaruhjegénggal saling

If already AF-story-Trans. which dirty-dirty so soon each other tembungin (8)

answer

'If they talk dirty things they will soon answer each other'

d. Yén tiang Ng-(k)eneh-ang boya sangkaning timpal-timpalé ugig (25)

If $1 \mathrm{SG}$ AF-mind-Trans. not because frind-friend ignorant 'According to me, it is not because our friends ignorant'

We can see that in data (5) a. the verb micayang comes from the noun pica 'gift' attached with suffix -ang and then added with prefix nasal becomes micayang 'give' or 'bestow'. -ang in this context implies that the action was done on the object. The word micayang itself means 'to give pica'. In (5) b, it can also be seen that the derived word ngortaang comes from the noun base orta 'news' added with the suffix -ang and then attached with prefix nasal so that it becomes ngortaang 'to talk about'. -ang in this context also functions as a transitive and it implies that the 
action is dedicated to the object of the sentence. The same case also happens to the word ngortaang 'talk about' in data (5) c and ngenehang 'think of' in d.

\subsection{2 - ang attached to adjectival base}

The suffix -ang attaches adjective based mostly expresses the meaning of 'making' or 'becoming' the meaning denoted by the adjective used in the word (the adjective base). Such a kind of derivation is commonly used in daily conversation. This can be seen in the following data.

(6) a. Tegeh-ang ngaé témbok!

High-Trans. make wall

'Make high wall!'

b. Ia ng-linggah-ang natah.

3SG AF-wide-Trans. yard

'He widened the yard'

It can be seen, like in example (6) a and b, -ang can attach an adjective to form a verb. The specific meaning implied in this derivation is 'to make something more...'. Tegehang, in (6) a, for example, may mean to make something more tegeh 'higher'. Nglinggahang in (6) b is also composed from the word linggah 'wide' attached with -ang added with nasal prefix so that it becomes nglinggahang 'to make something wider'. -ang in this case also implies the meaning of 'making something more..' As the word implied, nglinggahang means to make something wider.

\subsection{3 -ang attached to the adverbial base}

The suffix - ang added to the adverbial base can form a verb that expresses adverbial meaning, a verb that expresses how something is done. This is illustrated in the following data.

(7) a. Ia N-énggal-ang majalan maranepukin kuluk galak 3SG AF-slow-Trans. walk.way just see dog wild 'He slowed down his walk while seeing a wild dog'

b. Ban takut-né, ia ng-tengah-ang negak Because of afraid-POSS, 3SG AF-center-Trans sit 'Being so scared, he moved and sat to the center'

The word ngénggalang 'to speed up' in data (7) a is derived from the adverb enggal 'fast' attached with verbalizing suffix -ang and added with prefix nasal as a transitive. The derived verb ngénggalang implies the meaning of how the action takes place. It can be seen that ngénggalang in the data above expresses or modifies the verb majalan 'to walk'. It means it modifies how the action majalan takes place.

In data (7) b, it can also be seen that suffix -ang functioning as a transitive attaches to the adverbial tengah 'center' then added with prefix nasal and it becomes the verb ngtengahang which carries the meaning of moving to tengah 'center'. It implies how and to where the activity is done.

\subsection{4 -ang modifying intransitive verb}

Again when -ang is added to an intransitive verb it functions as a transitioning suffix. In this case -ang is used when the object is mobile. It is the object that is moved. Ang attaches intransitive verbs may express a causative meaning like in the following data.

(8) a. I mémé m-(p)ules-ang panak-né

Det. Mother AF-sleep-Trans. Child-POSS

'Mother slept her baby'

b. Belabar-é ng-anyud-ang punyan kayu-né ané gedé nto Flood-DEF AF-drift away-Trans. tree wood-DEF that big Det. 'The flood washed drifted away from the big tree'

Sujaya, N. ., \& Sukiani, N. K. . (2020). Derived verbs with suffix -ang in Balinese: syntactic and semantic analysis. International Journal of Linguistics, Literature and Culture, 6(6), 48-57. https://doi.org/10.21744/ijllc.v6n6.1036 
It can be seen that in (8) a the derived mulesang comes from the intransitive verb pules 'sleep' attached with the suffix -ang then added with prefix nasal becomes mulesang 'to sleep'. As a transitifyzing suffix -ang in this case express causative meaning. In (8) b, -ang attaches the intransitive verb anyud 'drift away' added with prefix nasal becomes nganyudang 'wash away'.

\subsection{Suffix -ang in imperative construction}

Imperative constructions use the base form. When -ang is added to the base form, especially to the imperative, suffix -ang does not carry any meaning. Syntactically, -ang on the base form verb may express that the sentence belongs to an imperative form. The verbs with -ang concentrate the action on the object.

\section{(10) a. Men kénkén keneh adi-né, $\quad$ tegarang sambat-ang! (2) So how mind brother-DEF try say-Trans. \\ 'So what do you think, try to mention it! \\ b. Yén mbok kondén teka jakan-ang adi-né \\ If sister not yet arrive cook-Trans. brother-POSS \\ 'If I have not arrived yet, cook rice for your brother'}

In data data above, we can see that the verb sambatang 'say' in (10) a is composed by the base sambat 'say' and attached with suffix -ang and the verb jakanang in (10) b is formed by the base verb jakan 'cook' attached with suffix -ang becomes jakanang 'cook for someone'. It can be noted here that besides as the marker of imperative sentence, -ang which also as applicative suffix implies benefactive meaning.

In Balinese, besides the base form, the imperative sentence may also be in the $\mathrm{N}$-form which may have no suffix or have ang or -in. It is the feeling of the speakers that determines which form is chosen. The following data are the imperative sentence with $\mathrm{N}$ - forms.

(11) Ideolas gatida m-(b)eli-ang panak-é manisan.

Please very don/t AF-buy-Trans child-POSS candy

'Pleas, don't buy our child candy'

Data (11) above shows that the nasal form meliang is derived from the base beli 'buy' attached with the suffix -ang and added with prefix nasal. This nasal form is used to express the imperative function.

When the imperative sentence is made negative, the word sampunang $(\mathrm{H})$ or $d a(\mathrm{~L})$ 'Don't' is used and put in front of the clause. These negative words are also used the third person verbs to make negative commands.

(12) a. Sampunang ng-raos-ang anak, tan patut nika

Don't AF-words-Trans. child not good that

'Don't talk about someone, it is not good'.

b. Nah, da buin lantang-ang-a. Ingong cocok (11)

Okay, don't again long-Trans.-clitic. 1SG agree

'Okay, don't say it again. I do agree'

In the data (12) a above we can see that the sentence belongs to a negative imperative sentence. It is identified by the occurrence of the word Sampunang 'don't' followed by the derived verb ngraosang which comes from the noun raos 'words' attached with -ang and added with prefix nasal and it becomes ngraosang 'talk about'. While in (12) b, the negative form is marked by the $d a$ 'don't.

\section{4 - ang in passive construction}

In Balinese, quite often such verbs have two objects, a person and a thing. In such construction the thing is expressed without a preposition and looks like a direct object; it is, however, a noun used adverbially. Balinese uses $\mathrm{Ka}$-baseang or Ka-base-in constructions to express passive sentences. If the person object is used as the subject of the passive 
construction, the thing object remains unchanged in form; if the thing object is to be the subject of the passive construction, the suffix used is -ang.

After the data were observed, there were some passive constructions of $k a$ - base -ang form found, with or without Agent. If it has an agent, normally it is expressed by preposition L tekén, baan, olih 'by', H antuk 'by'.

(13) a. Ditu nyen karirihan adi-né undukagama patut ka-sobyah-

ang (2)

There then knowledge brother-POSS about religion necessary Pass-

inform-Trans.

'There then your knowledge about religion should be spread'.

b. Gusti Ngurah Celuk sane waged ring sastra lan pascat ring payudan taler

Gusti Ngurah Celuk who good at literature and good at war also

ka-titah-ang dadostaméng (1)

Pass-order-Trans. as guard.

'Gusti Ngurah Celuk who was good at literature and war was also ordered

to be a guard'.

c. Raksasa Mangpiah lantas mabalik ngalih tongos timpal-né

Giant Mangpiah then return find place friend-POSS

mapupul disubané antar nyalanang tugas ané ka-titah-ang

gether after well doing duty that Pass.-rule-Trans.

olih Kala Bebau (16)

by Kala Babau

'The giant Mangpiah then returned back to find his friend's place to

gather after the did their duty which was ordered by Kala Babau'.

d. Duke malu, Raksasa Kala Bebau ka-kasor-ang olih Bhatara Indra dugas

Before, the giant Kala Babau Pass-defeat-Trans by Bhatara Indra

when

ngusak-asik mercapada (10)

disturb the universe.

'Before, Raksasa Kala Bebau was defeated by Bhatara Indra when he was trying to destroy the universe'.

In data (13) a and b we can see that the suffix - ang is used in passive construction using $k a$ - passive form. It can be seen that the verb kasobahyang 'be informed' in a is formed by the word sobyah 'inform' attached with the suffix ang and prefix $k a-$. The passive form, in this case, is marked by the occurrence of the prefix $k a$-. The same process of derivation also happens in b. Katitahang 'be ruled' is derived from the word titah 'rule'attached with the suffix -ang a prefix $\mathrm{ka}$ - as the marker of the passive sentence. We can also see these two data of passive with -ang do not have prepositional Agent. However, the passive forms with ka-base-ang, katitahang in (13) c and kakasorang in (13) d is followed by the prepositional phrase Agent using the preposition olih 'by'.

\section{Conclusion}

Considering and paying attention to the analysis above, it can be concluded that Balinese suffix -ang can attach the word class of noun, adjective, adverb, intransitive and transitive verb. Syntactically, it can occur in various constructions. In imperative construction, -ang does not express any meaning. It is just used for the emphasis that the sentence is in the imperative form. The important thing to distinguish between suffix -ang and suffix -in if it is followed by an object is that with -ang the object is mobile while with -in the object is immobile. Besides as transitivizing suffix, -ang when used aplicatively may express benefactive or causative meaning. The use of -ang in the sentence Ia meliang tiang baas 'He bought me some rice' expresses benefactive meaning. While -ang in the

Sujaya, N. ., \& Sukiani, N. K. . (2020). Derived verbs with suffix -ang in Balinese: syntactic and semantic analysis. International Journal of Linguistics, Literature and Culture, 6(6), 48-57. https://doi.org/10.21744/ijllc.v6n6.1036 
sentence Ia ngelutang anaké cenik anto ka méméné 'He made the child hug her mother' is used to express causative meaning.

Conflict of interest statement

The authors declared that they have no competing interests.

Statement of authorship

The authors have a responsibility for the conception and design of the study. The authors have approved the final article.

\section{Acknowledgments}

In this opportunity, I would like to thank Jro Mangku Alit (the priest of a Balinese family temple), Nyoman Juana (the head of Abian Kapas traditional village), Dewa Putu Sumantra (the expert of Balinese and Indonesian language), Ketut Subagia (a linguist), and other Balinese friends for being informants and giving information during conducting this study. 


\section{References}

Arka, I. W. (1998). From morphosyntax to pragmatics in Balinese: a Lexical-Functional approach (Doctoral dissertation, Department of Linguistics, Faculty of Arts, University of Sydney).

Arka, I. W. (2005). Speech levels, social predicates and pragmatic structure in Balinese: A lexical approach. Pragmatics, 15(2-3), 169-203.

Artawa, K. (1994). Ergativity and Balinese Syntax (disertasi) Melbourne: La Trobe University.

Artawa, K. (2013). The basic verb construction in Balinese. Voice variation in Austronesian languages of Indonesia, 5-27.

Barber, C.C. (1974). A Grammar Of The Balinese Language (Vol. 1 \& 2) Aberden University Library, Occasional Publication No.3.

Dixon, R. M. (2005). A semantic approach to English grammar. Oxford University Press.

Foley, W. A. (2009). Functional syntax and universal grammar. Cambridge University Press.

Friederici, A. D. (2004). Processing local transitions versus long-distance syntactic hierarchies. Trends in cognitive sciences, 8(6), 245-247. https://doi.org/10.1016/j.tics.2004.04.013

Hunter Jr, T. M. (1988). Balinese language: Historical background and contemporary state (Doctoral dissertation).

Indrawati, N. L. K. M. (2011). Konstruksi Verba Beeruntun Bahasa Bali (Kajian Semantik dan Sintaksis). Denpasar: Program Pascasarjana Universitas Udayana.

Intiana, S. R. H. (2017). The Affix me-/-kan and me (n)-/-kan in the Presidential Candidates' debate texts in 20142019: Morphology Observation on Derivation and Inflection. International journal of linguistics, literature and culture, 3(2), 66-77.

Kardana, I. N., \& Satyawati, M. S. (2014). Morphosyntax of Balinese reciprocal constructions. International Journal of Linguistics, 6(4), 168-180.

Kersten, D. (1984). Spatial summation in visual noise. Vision research, 24(12), 1977-1990. https://doi.org/10.1016/0042-6989(84)90033-6

Lambrecht, K. (1996). Information structure and sentence form: Topic, focus, and the mental representations of discourse referents (Vol. 71). Cambridge university press.

Melinger, A., \& Dobel, C. (2005). Lexically-driven syntactic priming. Cognition, 98(1), B11-B20. https://doi.org/10.1016/j.cognition.2005.02.001

Pratiwi, D. P. E., Arka, I. W., \& Shiohara, A. (2018). On the situated socio-cultural meaning of benefactives in Balinese.

Quirk, R. (2010). A comprehensive grammar of the English language. Pearson Education India.

Sedeng, I.N. (2007). Morfosintaksis Bahasa Bali Dialek Sembiran: Analisis TataBahasa Peran dan Acuan (Doctoral dissertation, Universitas Udayana).

Sujaya, N., \& Setyarini, N. K. (2020). Subordinating Conjunction Expressing Purpose and Reason Used in Some Novels.

Suryati, N. M. (1997). Verba Berkomplemen dalam Bahasa Bali. Bandung: Program Pascasarjana Universitas Padjajaran.

Van Valin, R. D., van Valin Jr, R. D., van Valin Jr, R. D., LaPolla, R. J., \& LaPolla, R. J. (1997). Syntax: Structure, meaning, and function. Cambridge University Press.

Wechsler, S., \& Arka, I. W. (1998). Syntactic ergativity in Balinese: an argument structure based theory. Natural Language \& Linguistic Theory, 16(2), 387-442.

Yalcinkaya, M., \& Singh, V. (2015). Patterns and trends in building information modeling (BIM) research: A latent semantic analysis. Automation in construction, 59, 68-80. https://doi.org/10.1016/j.autcon.2015.07.012

Yeh, J. Y., Ke, H. R., Yang, W. P., \& Meng, I. H. (2005). Text summarization using a trainable summarizer and latent semantic analysis. Information processing \& management,41(1), https://doi.org/10.1016/j.ipm.2004.04.003

Zupanc, K., \& Bosnić, Z. (2017). Automated essay evaluation with semantic analysis. Knowledge-Based Systems, 120, 118-132. https://doi.org/10.1016/j.knosys.2017.01.006

Sujaya, N. ., \& Sukiani, N. K. . (2020). Derived verbs with suffix -ang in Balinese: syntactic and semantic analysis. International Journal of Linguistics, Literature and Culture, 6(6), 48-57.

https://doi.org/10.21744/ijllc.v6n6.1036 